ESPAÇO TEMÁTICO: ESTADO, AUTORITARISMO E LUTA DE CLASSES

\title{
América Latina: capital e devastação social
}

\author{
José Fernando Siqueira da Silva ${ }^{1}$ \\ https://orcid.org/0000-0003-1040-9558 \\ ${ }^{1}$ Universidade Estadual Paulista, Faculdade de Ciências Humanas e Sociais, Departamento de Serviço Social, Programa de \\ Pós-graduação em Serviço Social, Franca, SP, Brasil \\ ${ }^{1}$ Universidade Federal de São Paulo, Programa de Pós-graduação em Serviço Social e Política Sociais, Santos, SP, Brasil
}

\begin{abstract}
América Latina: capital e devastação social
Resumo: O artigo analisa a América Latina no atual estágio de acumulação capitalista. O faz a partir de uma abordagem socio-histórica que recupera componentes da crítica à economia-política de Marx, bem como observações de parte de sua tradição sobre o imperialismo, o colonialismo, a dependência, a revolução burguesa realizada pela via colonial, a modernização conservadora e o desenvolvimento desigual e combinado. Nisto, a composição das classes dominantes e dos Estados latinoamericanos. O texto recupera a experiência latino-americana do autor e os estudos realizados em projetos de pesquisa por ele coordenados a partir de 2011 na área de Serviço Social.
\end{abstract}

Palavras-chave: América Latina. Autoritarismo. Estado e Classe.

\section{Latin America: capital and social desolation}

Abstract: This article analyzes the current stage of capitalist accumulation in Latin America. It relies on a socio-historical approach that engages with components of Marx's critique of the political-economy. Also, this work is based on observations from part of Marxist tradition on imperialism, colonialism, dependence, the bourgeois revolution carried out through colonialism, conservative modernization, and the unequal and combined development. In this, the composition of the dominant classes and Latin American states. The text blends the author's Latin American experience and the studies carried out in research projects he has coordinated since 2011 in the field of Social Work.

Keywords: Latin America. Authoritarianism. State and Class.

Recebido em 26.06.2020. Aprovado em 02.08.2020. Revisado em 04.09.2020.

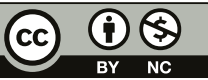

Este é um artigo publicado em acesso aberto (Open Access) sob a licença Creative Commons Attribution NonCommercial, que permite uso, distribuição e reprodução em qualquer meio, sem restrições desde que sem fins comerciais e que o trabalho original seja corretamente citado. 


\section{Introdução}

O tema proposto para o volume 24, número 1, da Revista Katálysis, intitulado "Estado, autoritarismo e luta de classes", é de extrema relevância. Ele convida à análise dos traços constituintes da história desta parte do continente americano, em particular a partir de 12 de outubro de 1492 quando Cristóvão Colombo avistou San Salvador, atual Bahamas. A colonização do cone centro-sul americano e do Caribe foi adensada pelos próprios espanhóis e pelos portugueses que dividiram suas posses na América Latina até a primeira metade do século XIX. É nesse contexto que povos e culturas aqui constituídos foram submetidos à força, vilipendiados, saqueados e dizimados. O colonialismo e a acumulação originaria do capital - ambos não situados apenas num passado distante - foram também aqui muito eficientes, seja para dividir povos nativos muito diversos, fragmentá-los para enfraquecê-los, seja para administrar a sangria desta parte da América associando convenientemente escravismo de nativos e negros, expropriação agrário-exportadora e produção voltada às zonas economicamente dominantes. Essa fórmula persiste até hoje, ainda que absolutamente reorganizada por múltiplas mediações impostas pelo capitalismo tardio (MANDEL, 1985) e suas crises cada vez mais estruturais (MÉSZÁROS, 2002).

Sendo assim, a natureza dos Estados, dos autoritarismos, das classes sociais aqui constituídas, das lutas aqui travadas e da destruição contínua de direitos não pode ser explicada pelo puro exercício da política, mas pela crítica à economia-política, ou seja, pela análise das condições reais que determinam a produção e reprodução da vida de seres humanos em condições históricas reais, nisto o trabalho como criador de valor, as carências e as necessidades aí contidas e a luta de classes que vem se constituindo nesse processo. Não se trata, aqui, de descaracterizar a dimensão política, mas de situá-la, enriquecê-la com múltiplas determinações econômicas que se impõem a partir de determinações socio-históricas muito precisas. Caberia perguntar: o que se entende por América Latina? O que se passa nessa parte centro-sul americano marcado por traços sociohistóricos comuns, realidades próximas e dinâmicas diversas? Como situá-la no atual estágio de acumulação capitalista e mensurar o impacto disto junto aos trabalhadores(as) latino-americanos(as) que vivem da venda da sua força de trabalho sob condições brutais e extremas? Quais as pistas para valorizar e sintonizar o legado crítico do Serviço Social com as imposições do atual cenário em curso? As respostas a essas questões, seguramente muito complexas, aportam o tema sugerido para este número da Revista e balizam o Serviço Social como profissão nesse contexto. Ousemos oferecer algumas pistas nesta direção.

\section{Acumulação e crise capitalista: o lugar da América Latina}

O debate atual sobre a América Latina, a crise capitalista que aqui impacta e a devastação social em curso - nisto as tensões do Serviço Social como profissão -, exige recuperar, ainda que sumariamente, alguns traços históricos estruturais importantes e necessários à explicação das condições atuais do cone centro-sul americano.

Em primeiro lugar, o mercantilismo alimentou a acumulação primitiva do capital baseada no capitalismo concorrencial-comercial adensado partir do século XVI (MARX, 1984a). Atualizou-se já no final do século XIX e início do século XX, época em que se reorganizou o colonialismo sob o comando do capitalismo monopolista/imperialista (LENIN, 2008) e da dependência constituída no contexto de duas grandes guerras mundiais. A financeirização (fusão entre capital industrial e bancário), a consolidação de monopólios, a exportação de capitais, a captura orgânica dos estados nacionais e dos fundos públicos, passaram a sustentar a trama imperialista-monopolista da nova fase da acumulação capitalista objetivada no alvorecer do século XX1 . Esta parte do continente americano, por sua vez, modernizou seu papel na engrenagem econômica mundial como região dependente e efetivou a superexploração da força de trabalho (MARINI, 2008) ${ }^{2}$. Isso gerou certo tipo de modernização, a conservadora, gestada na segunda metade do século XX, sob a ditadura do grande capital (IANNI, 2019). A dependência, aqui, não poderia gerar o desenvolvimento como corretamente insistiu Ruy Mauro Marini, mas desembocou em outro tipo de composição um tanto estranha: o "desenvolvimento" desigual e combinado (FERNANDES, 1968, p. 139-140; OLIVEIRA, 2003, p. 59-60)³. 
A posse de colônias é a única coisa que garante de maneira completa o êxito do monopólio contra as contingências da luta com o adversário, mesmo quando este procura defender-se mediante uma lei que implante o monopólio de Estado. Quanto mais desenvolvido está o capitalismo, quanto mais sensível se torna a insuficiência de matérias-primas, quanto mais dura é a concorrência e a procura de fontes de matérias-primas em todo o mundo, tanto mais encarniçada é a luta pela aquisição de colônias. (LENIN, 2008, p. 83).

Em segundo lugar, a revolução burguesa, nesta parte do globo, foi hipertardia e efetivou-se pela via colonial (FERNANDES, 1987 e 2009), ou seja, estruturou-se a partir da economia agrário-exportadora, responsável pela organização de um mercado essencialmente voltado aos interesses externos (portanto, deslocado e descomprometido com as necessidades latino-americanas). Sustentou-se na submissão generalizada, na escravidão e no genocídio de povos originários e negros africanos com profundas marcas patrimonialistas e patriarcais, bem como cicatrizes de um racismo estrutural (MOURA, 1983 e 1988), traços estes indeléveis de um colonialismo reatualizado e reafirmado - com outras mediações - no início do século XXI. Importante destacar que a burguesia latino-americana do século XX necessitou da decisiva intervenção dos estados nacionais fortes à acumulação e ao estímulo capitalista ${ }^{4}$, fossem esses explicitamente a favor do imperialismo ou mais próximos de projetos nacionais desenvolvimentistas com certa distribuição interna da riqueza. José Batlle y Ordóñez no Uruguai, Getúlio Vargas no Brasil e Juan Perón na Argentina (guardadas suas diferenças - temporais e conjunturais - e suas contradições), foram exemplos clássicos deste segundo caminho definitivamente derrotado pelas ditaduras cívico-militares impostas por todo centro sul americano a partir da metade dos anos 1960 (FERNANDES, 2009). O desfecho deste debate, travado predominantemente até os primeiros anos da década de 1960, é conhecido: a autocracia burguesa, a modernização conservadora e a "ditadura do grande capital" (IANNI, 2019, p. 27-89); a reedição da dependência, a recriação de estados autoritários e o triunfo do imperialismo liderado pelos Estados Unidos.

Em terceiro lugar, o agravamento da realidade latino-americana vincula-se estruturalmente ao capitalismo tardio (MANDEL, 1985) inaugurado a partir do fim da segunda-guerra mundial e da guerra fria, mas também é caudatário de sua crise estrutural (MÉZSÁROS, 2002) adensada no início dos anos 1970 que culminou com o projeto neoliberal. A ofensiva do capital se sustentou nas privatizações de instituições e de espaços públicos, na desregulamentação e flexibilização geral, na precarização laboral, na terceirização, na informalização (hoje, também uberizada - ANTUNES, 2018), no desemprego, na drenagem privada dos fundos públicos, na desestatização, na financeirização, na mercantilização de diferentes espaços da vida social e no paradigma do controle dos gastos públicos que afetam a afirmação de direitos fundamentais. István Mészáros (2002, p. 39-40, 49) faz o seguinte comentário sobre a expropriação predatória de recursos humanos e materiais do planeta no atual estágio de acumulação capitalista:

[...] reafirma-se implicitamente a viabilidade da emulação do desenvolvimento dos países "capitalistas avançados", sem levar em conta que nem as vantagens do passado imperialista, nem os imensos lucros obtidos da manutenção continuada do "Terceiro Mundo" na situação de dependência estrutural podem ser "universalmente difundidos" de modo a produzir os felizes resultados que se esperam da "modernização" e do "livre-mercado". [...] No período de ascendência global do capital, as crises irrompiam na forma de "grandes tempestades" (MARX), seguidas por fazes relativamente longas de expansão. O novo padrão, com o fim da era da ascendência histórica do capital, é a crescente frequência das fases de recessão tendendo a um continuum $^{5}$ em depressão.

É preciso ressaltar, em quarto lugar, que as velhas, requentadas e atuais formas de colonialismo, historicamente estabelecidas nas condições até aqui descritas, não foram impostas sem a resistência dos povos latino-americanos (originários ou aqui formados no processo de colonização). Afirmou-se tragicamente o uso explícito da violência, do saque e do genocídio por parte dos setores dominantes (SILVA, 2018). E os exemplos aqui são vastos: a) transitam da eliminação de povos nativos muito diversos que resistiram de diferentes formas à colonização (Tupis-guaranis, Mapuches, Wichis, Diaguitas - Quechuas, Quechuas Andinos -, Yamanas, Huarpes, Aimaras, Tobas, Onas, Calchaquíes, Matacos, Mazatecos, Comechingones, Yanomamis, Sanavirones, Quichuas, Man, Ashánincas, Xavantes, Yukpa, Paítavyterás, Pemóns, entre muitos outros); b) passam pela resistência dos povos negros escravizados (Quilombos dos Palmares, com Zumbi e a Revolução Haitiana 
- 1791, liderada por François-Dominique Toussaint Louverture, por exemplo); c) envolve povos e as lutas anticoloniais pela Pátria Grande latino-americana que se formaram a partir da mistura euro-afro-americana nativa (muitos deles liderados por Simon Bolivar, José Artigas, José Martin, José Martí, entre outros); d) se expressa no covarde massacre realizado pela coalisão Brasil-Argentina-Uruguai contra o Paraguai liderado por Solano Lopes na Guerra da Tríplice Aliança ou Guerra Grande (1864-1870); e) bem como possui amplo desenvolvimento ao longo do século XX por todo cone centro-sul da América, por meio de lutas antiditatoriais, movimentos armados, projetos anticapitalistas, anticoloniais e anti-imperialistas diversos, em que a experiência cubana de 1959 foi exemplar. E esses são alguns poucos e representativos exemplos ${ }^{6}$.

Em quinto lugar, não há como analisar o pauperismo, o autoritarismo, os estados e suas contradições, as classes, a luta entre elas e a reprodução do capital na América Latina, sem perquirir as entranhas desta realidade sumariamente aqui indicada, bem como sem criticar a ideologia que oculta, naturaliza, justifica, inverte e generaliza como verdade proposições estranhas aos grupos subjugados pelo capital e pelo capitalismo (MARX; ENGELS, 2007). Isso tudo nas condições do imperialismo, do neocolonialismo e da dependência na atualidade, sob o comando da fração financeira do capital. O desprezo disto frequentemente tem como consequência a descrição do imediatamente posto, a ênfase em um exercício científico amparado em diferentes formas de logicismo que ocultam o real e seu movimento e reeditam a razão miserável e sua decadência ideológica (PAULO NETTO, 1981, p 109-131). Portanto, o ponto de vista de totalidade (MARX, 1989; LUKÁCS, 2012) é absolutamente essencial para orientar metodologicamente essa empreitada, embora isso em hipótese alguma subsuma a própria dinâmica do real como "lógica da coisa" (MARX, 2005, p. 39). Trata-se, aqui, de produzir conhecimentos orientados pelo ponto de vista ontológico-materialista em que as representações do real não se confundem com o próprio real. Portanto, cabe à ciência reconstruir mentalmente a dinâmica objetivamente posta, historicamente situada e datada, como conhecimento real registrado teoricamente, afinado com a vida real de seres sociais históricos e reais, análise esta sujeita a correções e ajustes. O que vale aqui não é a exatidão desta reconstrução mental (impossível como tal), mas o exercício racional de perseguição do movimento do realmente posto. Como alertou Marx, "Toda ciência seria supérflua se a forma de manifestação e a essência das coisas coincidissem imediatamente." [...] (MARX, 1985, p. 71). E insistiu:

[...] a totalidade concreta, como totalidade de pensamento, como uma concreção de pensamento, é, na realidade, um produto do pensar, do conceber; não é de nenhum modo o produto do conceito que se engendra a si mesmo [...]. O todo, tal como aparece na cabeça, como um todo de pensamento, é um produto da cabeça pensante, que se apropria do mundo da única maneira em que o pode fazer, maneira que difere do modo artístico, religioso e prático-espiritual de se apropriar dele. O objeto real [realeSubjekt] permanece em pé antes e depois, em sua independência e fora da cabeça ao mesmo tempo, isto é, a cabeça não se comporta senão especulativamente, teoricamente [...] (MARX, 1989, p. 410-411).

É preciso reconhecer que as geniais observações marxianas sobre a lei geral da acumulação capitalista (MARX, 1984a), ou seja, a tentativa de administrar a dinâmica entre capital constante (voltado aos meios de produção) e capital variável (destinado à remuneração/manutenção da força de trabalho) - alterando a composição orgânica e técnica do capital em favor da acumulação -, sempre permite ampliar ou manter em níveis suportáveis a extração da mais-valia do trabalho (fonte do valor) e aumentar os lucros. Em tempos de contração, a gestão é feita no sentido de transferir os prejuízos das crises aos trabalhadores e trabalhadoras. As alternativas para lidar com as crises que fazem parte da acumulação capitalista são diversas: inserir tecnologia e reduzir força de trabalho (ou ampliá-la desde que aumentando a taxa de mais-valia); reduzir custos de produção em geral otimizando e ou diminuindo gastos com capital constante e principalmente variável; ampliar mercados seja para escoar estoques ou tecnologia obsoleta; aumentar a superpopulação relativa para forçar a queda dos salários; bem como compensar a queda na taxa de lucro por meio de ganhos financeiros, por exemplo. Para isso, conta com atores orgânicos típicos da fase monopolista-imperialista: o Estado (fortíssimo para o capital), os bancos e o complexo sistema financeiro. No geral, todo esse processo obedece a tendência de priorizar o capital constante em detrimento do capital variável e dos gastos dele derivados (custos com a reprodução da força de trabalho), administrando o exército industrial de reserva e aumentando a taxa de mais-valia. Em outras palavras, embora não exista um controle pleno da burguesia e de suas frações sobre os elementos que materialmente geram a acumulação e as crises, as classes dominantes tendem a influir nesse contexto para 
oferecer a melhor gestão possível da lei geral da acumulação como processo global. É neste cenário que o pauperismo relativo/absoluto cresce, já que a ordem do capital é essencialmente expropriadora e disso precisa para promover a acumulação subjugando, por meio de diferentes mecanismos, o trabalho.

Considerando dados dos últimos 40 anos sobre o Produto Interno Bruto (PIB) mundial divulgados pelo próprio Fundo Monetário Internacional (FMI) ${ }^{7}$, é possível verificar que as ondas longas de crescimento seguidas de crises de superacumulação típicas do pós-segunda guerra mundial, foram, no final do século XX, após a profunda restruturação produtiva do capital (de perfil explicitamente ultraliberal), substituídas por crescimentos mundiais baixos e quedas seguidas do PIB. Conforme o Gráfico 1, apresentado a seguir, entre 1980 e 2007 o crescimento real do PIB mundial (em cor laranja) associou baixo crescimento com sucessivas caídas, oscilando irregularmente (para cima e para baixo) entre 0,6\% (menor índice, entre 1981 e 1982) a 5,6\% (maior índice, entre 2006 e 2007), com quedas seguidas de 4,6\% para 2,1\% entre 1988 e 1993, com oscilações e baixo crescimento entre 1994 e 2000 e nova queda de 4,8\% para 2,5\% entre 2000 e 2001 . O avanço da economia mundial entre 2001 e 2007 de $2,5 \%$ a 5,6\%, não se sustentou e apresentou ligeira queda entre 2004 e 2005 (de 5,4\% para 4,9\%) e uma profunda crise em 2008 que levou a crescimento negativo de $0,1 \%$. A novidade de 2008 é que a crise nasceu, pela primeira vez, no centro do capitalismo mundial imediatamente identificada como uma bolha imobiliária do mercado norte-americano. De lá para cá a retomada mundial de 2009 não se sustentou: apresentou sucessivas quedas com ligeira estabilidade entre 2012 e 2016 (crescimento de cerca 3,5\%), pequena recuperação entre 2016 e 2017 (3,9\%) e nova baixa adensada brutalmente pela pandemia COVID-19 a partir de março de 2020 (com previsão negativa de -3\%) (REAL GDP growth, [2020])

\section{Gráfico 1 - Crescimento real do PIB}

IMF DataMapper

Real GDP growth (Annual percent change)

10

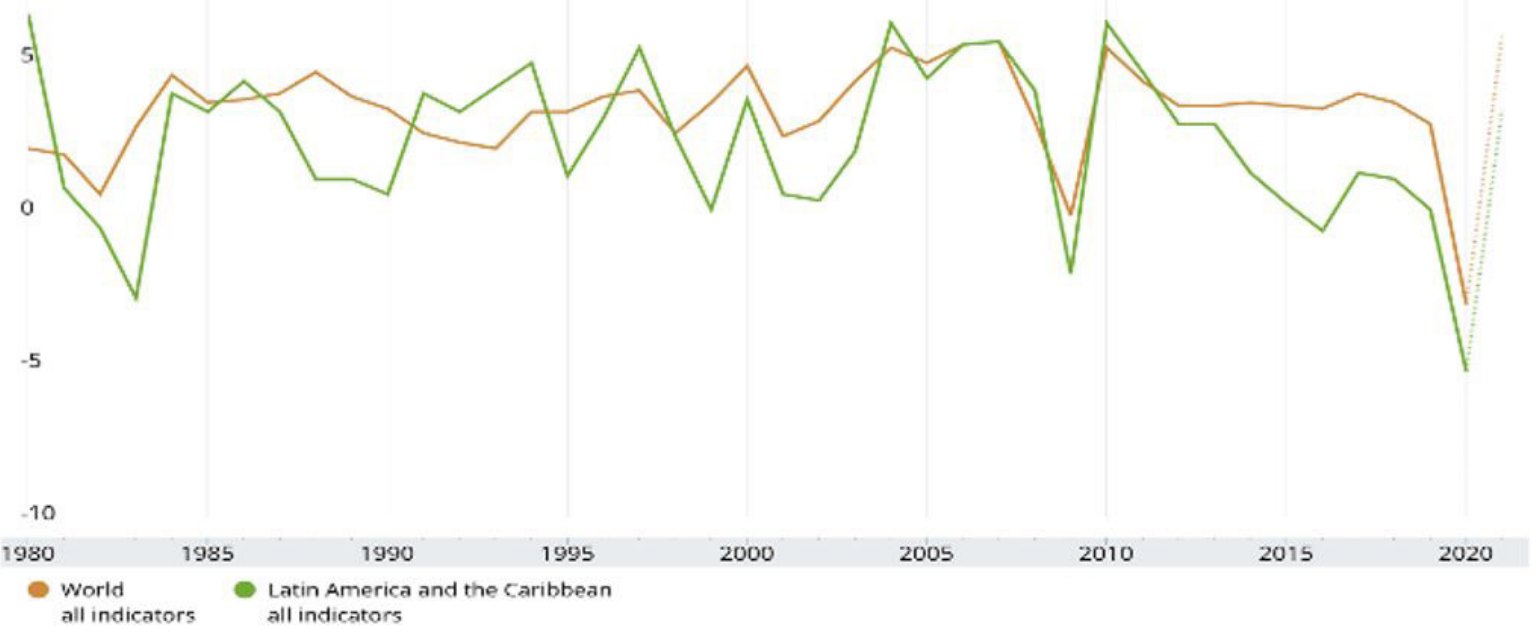

Fonte: Fundo Monetário Internacional

A situação da economia latino-americana (América do Sul, América Central e Caribe) é ainda mais grave. A linha verde do gráfico anteriormente exposto, mostra que nesta parte do continente americano os baixos índices de crescimento conviveram com instabilidades que se acentuaram nos últimos 40 anos. Os momentos de crescimento abrupto do Produto Interno Bruto (quase sempre marcado por índices modestos - ainda que acima da média mundial em momentos pontuais) são rapidamente substituídos por quedas mais fortes, ambos prioritariamente associados aos preços internacionais dos commodities ${ }^{9}$. Entre 1980 e 1983 houve uma abrupta caída do PIB de 6,5\% para -2,8\%, uma retomada a partir de 1984 de 3,9\%, ligeira estabilidade até 1986 e 
outra queda intensa até 1990 (atingindo o patamar de 0,6\%). Esta instabilidade persistiu ao longo dos anos 1990, apresentando números que oscilaram entre 5,4\% (melhor índice, 1997) a 0,1 (pior patamar, 1999). A oscilação, para cima e para baixo, persistiu até 2002, com rápido crescimento até 2004, ligeira estabilidade até 2007 e forte baixa com a crise mundial de 2008 atingindo o índice de $-2 \%$. A recuperação em 2009 não se sustentou e entrou em queda livre até 2016, com ligeira recuperação em 2017 (1,3\%) e abrupta caída agravada pela pandemia COVID 19 em 2020 (com previsão de -6\%) (REAL GDP growth, [2020]). Necessário ressaltar que estes números médios referentes à América Latina logicamente oscilam entre os países do bloco, ainda que no geral a curva de ascensão e de queda siga o padrão internacional: mais modestos nos momentos de crescimento mundial (quando acima da média mundial) e mais radicais nos momentos de depressão (abaixo da linha média mundial). É preciso destacar que tais números representam projeções realizadas na primeira metade de 2020. Dados atualizados, oficialmente divulgados pelo Instituto Brasileiro de Geografia e Estatística (IBGE) em agosto de 2020, indicam que o PIB brasileiro do segundo trimestre teve uma queda de $9,7 \%$ comparado com o mesmo período em 2019 ( 0,1 positivo - o que revela a gravidade de um cenário já em curso antes da pandemia). Informações revisadas sobre o primeiro semestre de 2020, apontam uma queda ainda maior do que havia sido projetado: -2,5\% comparado com o mesmo período de 2019.

Tomando como exemplo as três maiores economias do bloco e o mesmo período (1980-2020), é possível verificar os seguintes índices divulgados pelo FMI no mesmo site indicado na nota de rodapé número 6: a) o Brasil teve os maiores picos positivos do PIB nos períodos de 1984-1985 (7,9\%), 1993-1994 (5,8\%), 2003$2004(5,8 \%)$ e 2006-2007 (6,1\%) e, por sua vez, baixas mais significativas em 1980-1981 (-4,4\%), 1982-1983 (-3,4\%), 1989-1990 (-4,2\%), 2008-2009 (-0,1 - a conhecida marolinha, assim chamada pelo presidente Lula), $2015(-3,6)$ e 2020-2021 (previsão de -5,3\%); b) a Argentina apresentou índices positivos nos períodos de 1985-1986 (7,1\%), 1990-1991 (10,5\%), 1996-1997 (8,1\%), 2002-2003 (9,0\% - após a gravíssima crise de 2001-2002) e 2009-2010 (10,1\% - após a profunda crise mundial de 2008), bem como índices mais baixos em 1980-1981 (-5,7\%), 1984-1985 (-7\%), 1988-1989 (-7\%), 1994-1995 (-2,8\%), 1998-1999 (-3,4\%), 2001-2002 $(-10,9 \%), 2008-2009(-5,9 \%)$, com crescimento negativo ou baixo crescimento entre 2012 e 2020 e previsão de -5,7\% para 2020-2021; c) o México obteve seus melhores índices nos períodos de 1983-1984 (3,4), 1989$1990(5,2), 1995-1996(6,8), 1999-2000$ (4,9) e 2009-2010 (5,1 - após a crise mundial de 2008), apresentando os valores mais baixos em 1982-1983 (-3,5), 1985-1986 (-3,1), 1994-1995 (-6,3), 2000-2001 (-0,4), 20082009 (-5,3 - igualmente após a crise mundial de 2008) e entre 2011-2020 com tendência de queda do PIB associadas a baixos crescimentos e uma previsão de -6,6\% após os efeitos da pandemia de 2020 (REAL GDP growth, [2020]). Essa tendência, com algumas variações, como curva geral, segue o mesmo padrão por todos os países da região, adensando-se em situações especiais: historicamente Cuba e mais recentemente Venezuela, exemplos de embargos econômicos mais intensos liderados pelos EUA.

A taxa de desemprego, também baseada em dados do FMI (Gráfico 2), considerando que esse índice não apanha a informalidade, a precarização da força de trabalho empregada e a intensificação laboral (aspectos essenciais e em amplo crescimento), foi nitidamente afetada pelos momentos de expansão e de crise, manejada pela gestão da composição orgânica do capital que tende a afetar negativamente regiões como a América Latina. A tendência geral de queda do desemprego a partir de 2003 em países da região tais como como Brasil, Argentina, Uruguai, Paraguai, Chile, Bolívia, Equador e Colômbia, por exemplo, precisa considerar que os empregos aí criados ocorreram sob as condições da flexibilização laboral neoliberal (portanto, seguramente mais precarizados), em Estados orgânicos ao capital monopolista-financeiro (mesmo nas suas versões mais progressistas) e focais no trato do pauperismo extremo (ainda que com recuperação do salário mínimo) ${ }^{10}$. Isso significou, em diferentes medidas na região, não propriamente a diminuição da desigualdade social, mas a inserção provisória de parte das camadas mais pobres dos trabalhadores no consumo interno. Todavia, após a crise mundial de 2008 nascida no ninho do capitalismo mundial e as sucessivas tentativas dos governos latino-americanos para contê-la (vários deles de perfil progressista), o desemprego deu sinais de crescimento em 2013 e aprofundou-se explicitamente a partir de 2015 em praticamente toda a região, aperfeiçoado pela precarização e rápida tendência de desregulamentação laboral, com perspectivas devastadoras - ainda não exatamente mensuradas - após a pandemia COVID 19.

Ora, o que mostram esses números sinteticamente? Os últimos 40 anos, na esteira da ordem monopólicoimperialista do capital típica da transição do século XIX para o século XX, das duas guerras mundiais produzidas neste contexto, do modelo de desenvolvimento do pós-segunda-guerra e de sua crise já sentida no início da 


\section{Gráfico 2 - Taxa de desemprego}

IMF DataMapper

Unemployment rate (Percent)

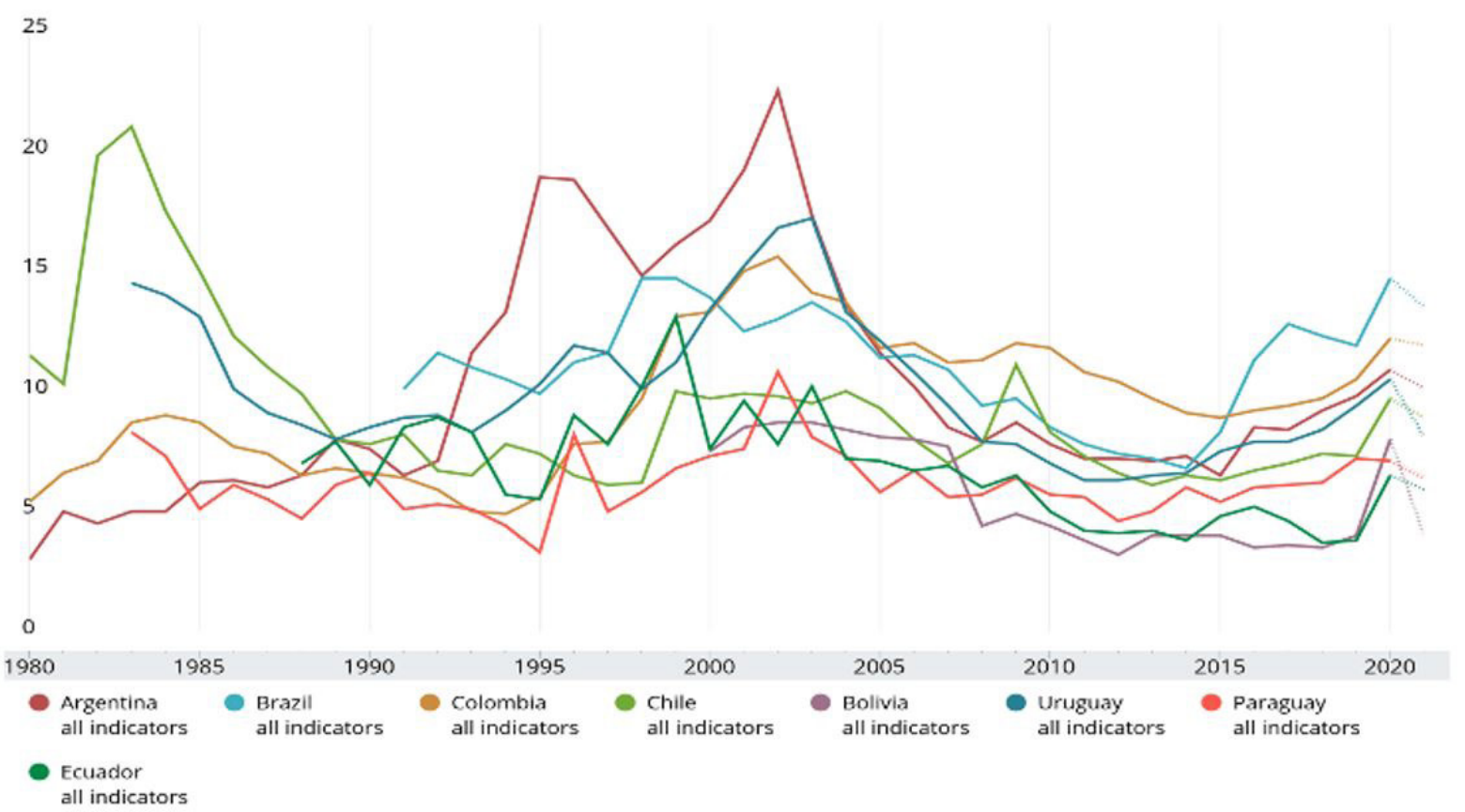

Fonte: Fundo Monetário Internacional

década de 1970 (MANDEL, 1985), do fim da guerra-fria e da adoção de um projeto neoliberal (que transitou da base fordista-keynesiana para o toytotismo-ultraliberal - não sem composições frankensteinianas na periferia do capitalismo), estão sendo marcados pela tendência em substituir onda longas de crescimento seguidas por crises de superprodução, por um cenário de baixo-crescimento mundial associado a crises cada vez mais regulares e profundas (inclusive nascidas no centro do capitalismo mundial) ${ }^{11}$. A trágica história latino-americana tem reproduzido, no passado recente (1980-2020), uma instabilidade econômica marcada pela dependência reconfigurada no contexto da ordem monopólico-financeira do capital e por profundas desigualdades sociais que se reconfiguram na esteira da tradição colonial, ou seja: a) maciçamente exportadora de produtos primários (agro minerador); b) fomentadora de governos locais frequentemente autoritários, subjugados aos interesses internacionais e protetores das elites internas a eles associadas, burguesias completamente descomprometidas com os interesses da América Latina e avessas a reformas minimamente democráticas; c) sociedades que recolocam e reatualizam a superexploração da força de trabalho (MARINI, 2008) sob bases racistas MOURA, 1988), sexistas (FEDERICI, 2019) e anti-latino-americanas; d) constantes e bruscas oscilações econômicas marcadas pela incapacidade de manter padrões de desenvolvimento sólidos e persistentes, promotora da desindustrialização ou da simples não industrialização de países da região ${ }^{12}$; e) ênfase na modernização conservadora comprometida com a criação das bases necessárias à atualização constante da dependência como desenvolvimento desigual e combinado (FERNANDES, 1968; OLIVEIRA, 2003).

\section{Radicalização à direita: o crescimento do conservadorismo reacionário}

Embora não seja simples indicar os elementos centrais que elucidem as bases da ofensiva da direita e de sua fração mais radical na América Latina, alguns aspectos devem ser aqui sumariados. Eles possuem, pelo menos, dois eixos de sustentação que recuperam traços essenciais da história latino-americana (desenvolvidos no item anterior): a) o perfil da burguesia e de suas frações constituídas sob as bases do imperialismo, da 
dependência e da modernização conservadora desigual e combinada, hoje sob o comando da fração financeira do capital. As classes dominantes latino-americanas se constituíram a partir da base material que marcou a revolução burguesa aqui realizada hipertardiamente, pela via colonial (FERNANDES, 1987); b) a reestruturação produtiva crescente e em curso desde os anos 1970/1980 no contexto da crise estrutural do capital, do fim dos quase 30 anos gloriosos de crescimento mundial e do processo de redemocratização política na América Latina a partir da segunda metade dos anos 1980 que gerou outro pacto social no período pós-ditatorial (explicitamente rompido de 2012/2013 para cá). O receituário neoliberal foi fortemente materializado nos anos 1990 por toda essa região e reatualizado - em diferentes medidas - a partir dos anos 2000, seja sob o comando de governos pactuados mais progressistas ou de projetos governamentais genuinamente de direita gradativamente mais fortalecidos a partir do impacto da crise estrutural do capital em $2011^{13}$.

Ora, considerando o que já foi exposto, ou seja, a tendência de alterar a composição orgânica e técnica do capital sustentada no incremento do capital constante em detrimento do capital variável, em outras palavras, na articulação entre aperfeiçoamento tecnológico e redução dos custos com trabalho vivo - com o objetivo de retomar níveis ótimos de acumulação como tendência geral -, as consequências das políticas à direita tendem a recrudescer mundialmente (não sem resistências). Na América Latina o cenário é mais drástico e dramático, considerando a tendência histórica em remunerar a força de trabalho abaixo de seu valor médio de reprodução (MARINI, 2008), o que determina contornos ainda mais trágicos para a informalização, terceirização, uberização e outras formas precárias de exploração. Junta-se a isso alguns outros traços determinantes:

a) estados nacionais explicitamente fortes ao capital e débeis ao trabalho (característica esta mundial, mas especialmente radicais na América Latina), componente este orgânico à acumulação capitalistamonopolista, mas com consequências sociais regionais ainda mais devastadoras;

b) nisto, burguesias descomprometidas com processos de democratização do centro sul latino-americano, mesmo na sua forma mais elementar - a democracia política -, região frequentemente e historicamente vista como foco de instabilidades sociais que devem ser objeto constante da contrarrevolução preventiva (FERNANDES, 1987);

c) a rapina e a violência na disputa pelos fundos públicos em regiões como a América Latina tendem a ser muito mais intensas. Isso cria condições objetivas e subjetivas que estimulam procedimentos autoritários que também se expressam na luta pela hegemonia dos estados por meio de projetos governamentais e sociais genuinamente de direita e ou de extrema direita;

d) esse complexo processo, apontado no item c, edificado no processo de crise estrutural do capital, tende a agravar-se substancialmente nesta etapa da acumulação capitalista explicitamente marcada por baixos crescimentos, por curto espaço de tempo, seguida por crises importantes que atingem não apenas a periferia do capitalismo mundial;

e) a histórica, precária, frágil e até inexistente proteção social latino-americana - no limite atrelada à gestão da pobreza extrema e à ausência se serviços públicos voltados aos direitos sociais -, tende a fragilizar-se ainda mais, fato que adensa a catástrofe em curso.

Embora não se trate de um assunto absolutamente novo, esse contexto contém novas mediações que precisam ser reveladas. Florestan Fernandes (2009), em um conjunto de conferências sobre a América Latina proferidas ao longo dos anos 1960, expõe com precisão o eixo que continua sustentando o velho-novo problema:

Os países latino-americanos enfrentam duas realidades ásperas: 1) estruturas econômicas socioculturais e políticas internas que podem absorver as transformações do capitalismo, mas que inibem a integração nacional e o desenvolvimento autônomo; 2) dominação externa que estimula a modernização e o crescimento nos estágios avançados do capitalismo, mas que impede a revolução nacional e uma autonomia real. Os dois aspectos são faces opostas da mesma moeda. A situação heteronômica é redefinida pela ação recíproca de fatores estruturais e dinâmicos, internos e externos. Os setores sociais que possuem o controle das sociedades latino-americanas são tão interessados e responsáveis por essa situação quanto os grupos externos, que dela tiram proveito. Dependência e subdesenvolvimentos são um bom negócio para os dois lados. Entretanto, sob as condições históricas atuais, o novo padrão de imperialismo e a hegemonia dos Estados Unidos colocam uma questão dramática: podem os países latino-americanos atingir realmente a integração nacional e a autonomia econômica, sociocultural e política através do capitalismo? (FERNANDES, 2009, p. 34). 
Seguramente, hoje, a hegemonia norte-americana está em jogo. O capitalismo, também, não conta com a mesma potência para gerenciar suas crises. A China é a maior ameaça e os efeitos das depressões não afetam apenas a periferia do capitalismo. Mas isso, em absoluto, põe em xeque o imperialismo ou altera a argumentação essencial contida na reflexão de Florestan Fernandes. Reafirma as teses marxianas sobre as contradições internas do capital e sua tendência em penalizar crescentemente as camadas trabalhadoras no processo de centralização e de concentração contínua de capitais. E a pergunta anunciada por Florestan é mais do que pertinente: "podem os países latino-americanos atingir realmente a integração nacional e a autonomia econômica, sociocultural e política através do capitalismo?" De nossa parte a resposta é não! E o atual momento reafirma essa direção. A luta por direitos, por democracia (no seu sentido pleno), a autêntica liberação nacional e latino-americana é uma luta anticapitalista progressista e anti-imperialista (nisto, antirracista, antissexista e antipatriarcal). E não há outra saída para a América Latina. Mesmo as formas mais elementares de participação e de gestão da desigualdade social estão severamente comprometidas, seja pela feroz disputa pelos fundos públicos, seja pelo adensamento de projetos governamentais explicitamente genocidas e ou ultraliberais politicamente corretos, discursivamente humanos.

O recrudescimento autoritário na América Latina, ainda que diverso, tem objetivo definido: implantar governos genuinamente comprometidos com a pauta imperialista e ultraliberal, ou seja, romper a política de conciliação de classes iniciada na segunda metade dos anos 1980, ampliar o avanço do capital sobre o trabalho, privatizar e acelerar a drenagem dos fundos e dos recursos públicos (financeiros e naturais). Essa voracidade desmoraliza e até criminaliza direitos, bem como precariza ainda mais as ações que regulam o pauperismo extremo. Ou seja, é preciso terminar o serviço iniciado com o velho projeto neoliberal dos anos 1980/1990 radicalizando sua intensidade junto aos trabalhadores (as) e aos estados. Isso significou, na prática, a intensificação das privatizações, a regularização da precarização laboral absoluta (informalização, uberização, terceirização e precarizações diversas), a devastação radical de direitos (saúde, educação e previdência social, em especial - onde já não eram privatizados) e o avanço sobre os recursos naturais desta parte do continente americano (cuja região amazônica é absolutamente estratégica). Despublicizar e mercantilizar esses espaços é o objetivo.

Como realizar isso sem contar com governos locais e regionais genuínos? Não por acaso Mauricio Macri, sob forte impacto midiático, se elegeu em 2015 prometendo uma nova Argentina com seu lema "cambiemos" (derrotado em 2019); golpes de estado foram implementados em Honduras (2009 - Manuel Zelaya), na Bolívia (2019 - Evo Morales) $)^{14}$, no Brasil (2016 - Dilma Rousseff) e no Paraguai (2012 - Fernando Lugo); violências têm sido sistematicamente cometidas no Chile de Piñera, onde forte resistência popular ocorreu no segundo semestre de 2019 que culminou com um vitorioso plebiscito em que 78\% da população chilena optou por alterar a constituição do país oriunda do governo Pinochet; a Colômbia tem eliminado lideranças progressistas e se rearmado fortemente sob a liderança local de Iván Duque; o Perú, desde março de 2018, segue caminho similar sob o comando de Martín Vizcarra; a Venezuela vem sendo emparedada por meio de um embargo que até então era privilégio de Cuba, defendendo-se com apoio do império em ascensão: o Chinês-Russo que também tem influído na Nicarágua liderada pelo líder sandinista Daniel Ortega e, já há algum tempo, tem impactado Cuba; o Equador rapidamente ajustado no governo de Lenin Moreno; mais recentemente, Carlos Alvarado Quesada assumiu a presidência na Costa Rica (2018), Nayib Bukele se elegeu em El Salvador (2019), Laurentino Cortizo no Panamá (2019 - seguindo larga tradição de apoio ao imperialismo dos EUA no país); e, os recém empossados (2020) Alejandro Giammattei (Guatemala) e Lacalle Pou (Uruguai), este último porta-voz do capital nas bandas do oriente por meio da Ley de Urgente Consideración. Situações absolutamente peculiares se reproduzem em Belize cujo país possui um governador geral comandado pela Monarca Inglesa Elisabeth II, Porto Rico (anexado pelo EUA sem os devidos benefícios para tal) e as devastadas ilhas caribenhas: Jamaica, República Dominicana e Haiti (essa última ícone da primeira revolução anticolonial e antiescravista latinoamericana). Finalizando, a tragédia se intensifica no Brasil de Jair Bolsonaro (eleito em 2018), um governo explicitamente protofacista (FONTES, 2019), propagador do lema “Deus, Pátria e Família", articulando base popular, autoritarismo, militarismo, obscurantismo, fundamentalismo religioso, irracionalismo e mídias sociais - para além do espaço formal - financiadas por grupos de extrema direita, mas explicitamente neoliberais e subservientes ao imperialismo dos EUA. Isso, por si só, mostra que o velho-novo fascismo brasileiro somente poderá ser devidamente elucidado na dialética entre marcas históricas inelimináveis e sua modernização sob condições atuais sustentadas por traços anteriormente inéditos. 
Ainda que importantes resistências venham se expressando em relativas vitórias locais e regionais (particularmente na Bolívia, no Chile e na Argentina), seria ingênuo não reconhecer a ofensiva do capital sobre o trabalho e suas expressões nos diversos governos que ocupam boa parte dos estados latino-americanos (mais intensamente de 2011 para cá). É necessário ressaltar que este paradigma tem reafirmado tragicamente, nas condições atuais, históricas desigualdades, com isso as inúmeras e diversas resistências a ele. $\mathrm{O}$ atual cenário tem revelado fissuras entre os setores que formam a direita mundial e latino-americana, o que significa que o atual cenário põe em questão as estratégias a serem utilizadas pelos setores conservadores e ou conservadoresreacionários para gerenciar a crise estrutural do capital ${ }^{15}$. A eleição de Joe Biden nos EUA expressa, nas condições particulares do império decadente, esta disputa financiada e acompanhada de perto pelos representantes do grande capital. Não se trata de celebrar a vitória democrata, mas a derrota eleitoral de Donald Trump ${ }^{16}$. Isto no exato sentido de combater a extrema direita e criticar a direita democrata que seguramente terá seus filhotes latino-americanos. Uma unidade crítica e programática das esquerdas é mais do que necessária. Ela deve ter base mundial e expressões regionais e locais, o que se impõe como tarefa complexa e urgente.

A velha e extinta luta de classes se reafirma! A toupeira abala o terreno! Marx (1984a, 1984b, 1984c) tinha razão: as mesmas condições necessárias à acumulação permanente e ampliada do capital, recriam, sob condições históricas diversas, novas contradições insuperáveis sobre as fronteiras do capitalismo. Ainda que a sociedade do capital tenha demonstrado um fôlego impressionante na gestão de suas crises, as condições reais para tal têm diminuído (tese defendida por Marx em O Capital). A luta pela emancipação social (política e humana-MARX, 2009) de homens e de mulheres latino-americanos (as) é uma luta seguramente mundial e anticapitalista progressista. Precisa incorporar criticamente, todavia, as diversas experiências de resistência aqui historicamente construídas, bem como pautas genuinamente humanas: lutas antirracistas, feministas, por igualdade diversas e defesa de nossos recursos naturais.

\section{Considerações finais}

Caberia, aqui, para finalizar, sumariar as condições reais para balizar um reposicionamento crítico do Serviço Social na América Latina, ressaltando que se trata de uma profissão cuja gênese vincula-se à ordem monopólica do capital e é formada por um leque extremamente heterogêneo de orientações teórico-práticas no seu interior, nem todas vinculadas à efetiva defesa da vida das diversas frações da atual classe trabalhadora.

Mais do que nunca, reafirmar a tradição anticapitalista progressista é o caminho mais promissor para que o Serviço Social contribua com lutas civilizatórias, como profissão, com os enormes embates já em curso dentro e fora de suas fronteiras. Para essa tradição é caminho necessário endossar e reatualizar a crítica ao capital e à sociedade que permite sua reprodução (o capitalismo), não como exercício logicista/especulativo, mas como base para subsidiar a decodificação da realidade objetivamente posta por toda a América Latina (como razão ontológica - LUKÁCS, 2010, 2012, 2013). Necessário decodificar a produção e a reprodução do pauperismo no atual estágio de acumulação capitalista (nisto as refrações particulares da questão social como expressão da Lei Geral da Acumulação Capitalista - MARX, 1984a), as determinações da profissão, suas demandas, limites e potencialidades objetivas, seus embates internos e possíveis rearticulações. É neste contexto que o trabalho profissional, o assistente social como trabalhador (a) e o Serviço Social como profissão (IAMAMOTO, 2007; RAICHELIS, 2020; SILVA, 2013 e 2020) - nas condições do capitalismo dependente e do desenvolvimento desigual e combinado latino-americano -, podem ser objetivamente analisados e criticados, bem como subsidiarem ações político-profissionais necessárias e úteis. Sem isso, a profissão tende a ser dragada não apenas pelas duras condições que já há algum tempo atuam sobre ela, mas também pelas fragilidades daqueles que ajudam a operar a desigualdade social (e aqui o desafio é enorme).

Não reconhecer o duro cenário em curso e não reavaliar criticamente a inserção profissional nesse contexto será fatal para os segmentos mais progressistas do Serviço Social, especificamente para sua fração mais crítica. As ações da burguesia mundial e de suas frações no contexto da crise mundial e estrutural do capital, em particular na América Latina, revela que a incompatibilidade estrutural entre acumulação capitalista e afirmação de direitos é uma realidade (SILVA, 2013). O avanço da direita genuína e da extrema-direita, adaptado às nossas condições socio-históricas dependente, escancara a barbárie em curso. Se por um lado urge o combate radical aos setores neoconservadores que crescem dentro e fora do Serviço Social, por outro lado é 
preciso ampliar o debate crítico e fundamentado, inspirado no ponto de vista da totalidade, com setores sociais civilizatórios, adensando e articulando demandas progressistas junto à classe trabalhadora hoje extremamente diversificada (ANTUNES, 2018). E aqui o leque é enorme no cenário geral de alteração na composição orgânica e técnica do capital necessária à retomada da acumulação: formais precarizados(as), informais, terceirizados, uberizados, desempregados (oscilantes ou permanentes), entre outros(as) que, importante ressaltar, imbrica-se com demandas particulares de mulheres, negros(as), povos originários, diversidade sexual, entre outras pautas que precisam articular-se com a luta classista. A profissão tem muito a contribuir com isso em espaços sociais em que a classe trabalhadora se faz presente: nas diferentes instituições que lidam com a gestão da pobreza, na área da assistência social (nos níveis federal, estaduais e municipais) e no sistema público de atendimento a direitos, mesmo considerando a brutal fragmentação do atual mercado de trabalho e a precarização na contratação da força de trabalho dos(as) assistentes sociais. Os segmentos organizados e progressistas do Serviço Social não podem desconsiderar essa imposição da realidade no processo de análise do real e na formulação de alternativas profissionais.

A barbárie está posta há algum tempo. Nela, o desespero e o medo alimentam formas atualizadas inspiradas no fascismo. Alguém duvida dessa possibilidade? Mas não se trata de um caminho inevitável, embora seguramente esteja em curso e possa consolidar-se.

\section{Referências}

ANTUNES, R. O privilégio da servidão. São Paulo: Boitempo, 2018.

CARDOSO, F. H.; FALETTO, E. Dependência e desenvolvimento na América Latina. 8. ed. Rio de Janeiro: Civilização Brasileira, 2004. FERNANDES, F. A revolução burguesa no Brasil; ensaio de interpretação sociológica. 3. ed. Rio de Janeiro: Guanabara, 1987.

FERNANDES, F. Capitalismo dependente e classes sociais na América Latina. São Paulo: Global, 2009.

FERNANDES, F. Sociedade de classes e subdesenvolvimento. Rio de Janeiro: Zahar, 1968.

FONTES, V. El proto-fascismo: núcleo central del gobierno Bolsonaro. Trasversales, 46, 2019. Disponível em: http://www.trasversales. net/t46vfontes.pdf. Acesso em: 28 jul. 2020.

IAMAMOTO, Marilda Villela. Serviço Social em tempo de capital fetiche - capital financeiro, trabalho e questão social. São Paulo, Cortez Editora, 2007.

IANNI, O. A ditadura do grande capital. São Paulo: Expressão Popular, 2019.

LENIN. V. I. O imperialismo: fase superior do capitalismo. 4. ed. São Paulo: Centauro, 2008.

LUKÁCS, G. Para uma ontologia do ser social I. São Paulo: Boitempo, 2012.

LUKÁCS, G. Para uma ontologia do Ser Social II. São Paulo: Boitempo, 2013.

LUKÁCS, G. Prolegômenos para uma ontologia do ser social. Tradução de Carlos Nelson Coutinho. São Paulo: Boitempo, 2010.

MANDEL, E. O capitalismo tardio. São Paulo: Nova Cultural, 1985.

MARINI, R. M. América Latina, dependencia y globalización. Bogotá: CLACSO y Siglo del Hombre Editores, 2008.

MARX, K. O método da economia política. In: FERNANDES, F. (org.). Marx e Engels: história. 3. ed. São Paulo: Ática, 1989.

MARX, K. Crítica da filosofia do direito de Hegel. São Paulo: Boitempo, 2005.

MARX, K. O capital: crítica da economia política. São Paulo: Abril Cultural, 1984a. v.1, t. 2.

MARX, K. O capital: crítica da economia política. São Paulo: Abril Cultural, 1984c. v.3, t. 1.

MARX, K. O capital: crítica da economia política. São Paulo: Abril Cultural, 1985. v. 3, t. 2.

MARX, K. O capital: crítica da economia política. São Paulo: Abril Cultural, 1984b. v. 2.

MARX, Karl. Para a questão judaica. São Paulo: Expressão Popular, 2009.

MARX, K.; ENGELS, F. A ideologia alemã. São Paulo: Boitempo, 2007.

MÉSZÁROS. I. Para além do capital. São Paulo: Boitempo, 2002.

MOURA, Clóvis. Brasil: raízes do protesto negro. São Paulo: Global, 1983.

MOURA, Clóvis. Sociologia do Negro Brasileiro. São Paulo Ática editora. 1988.

PAULO NETTO, J. Lukács. São Paulo: Ática, 1981.

OLIVEIRA, F. de. Crítica à razão dualista: o ornitorrinco. São Paulo: Boitempo, 2003.

RAICHELIS, R. Atribuições e competências profissionais revisitadas: a nova morfologia do trabalho no Serviço Social. In: CONSELHO FEDERAL DE SERVIÇO SOCIAL (org.). Atribuições privativas do/a assistente social em questão. Brasília, CFESS, 2020. v. 2. Disponível em: http://www.cfess.org.br/arquivos/CFESS202-AtribuicoesPrivativas-Vol2-Site.pdf. Acesso em: 28 jul. 2020. 
REAL GDP GROWTH. International Monatary Fund, [2020]. Disponível em: https://www.imf.org/external/datamapper/NGDP_RPCH@ WEO/OEMDC/ADVEC/WEOWORLD. Acesso em: 28 jul. 2020.

SILVA, J. F. S. Serviço Social: resistência e emancipação? São Paulo: Cortez, 2013.

SILVA, J. F. S. Sociedade do capital, violências e práxis profissional. Juventudes, violências e políticas publicas. Porto Alegre: EDIPUCRS, 2018.

SILVA, J. F. S. Trabajo social y crítica marxista. Propuestas críticas en Trabajo Social. Santiago: Revista del Departamento de Trabajo Social de la Universidad de Chile, número 1, 2020. (prelo)

THE WORD BANK. Brasil: aspectos gerais. O Banco Mundial no Brasil, 2019. Disponível em: https://www.worldbank.org/pt/country/ brazil/overview. Acesso em: 28 jul. 2020.

\section{Notas}

1 "Concentração da produção; monopólios que resultam da mesma; fusão e junção de bancos com a indústria: tal é a história do aparecimento do capital financeiro e daquilo que este conceito encerra [...]. O capital financeiro é força tão considerável, pode dizer tão decisiva, em todas as relações econômicas e internacionais, que é capaz de subordinar, e subordina realmente, mesmo os Estados que gozam da independência política mais completa [...]”. (LENIN, 2008, p. 47, 82).

2 Dependência entendida como "[...] relación de subordinación entre naciones formalmente independientes, en cuyo marco las relaciones de producción de las naciones subordinadas son modificadas o recreadas para asegurar la reproducción ampliada de la dependencia”. (MARINI, 2008, p. 111). Superexploração analisada tanto como pagamento da força de trabalho abaixo do valor médio necessário à sua reprodução, mas também, ao mesmo tempo, como sua extrema exploração e desgaste por meio da inserção de tecnologias no processo de modernização conservadora, seja como mais-valia absoluta ou relativa.

3 Vale indicar, sumariamente, a influência do pensamento de Trotsky (1985) no debate sobre a dependência latino-americana, particularmente nas ideias de Florestan Fernandes e nos estímulos aos estudos de Ruy Mauro Marini e de seu grupo (sumariamente descartado deste debate no Brasil). Cardoso e Faletto (2004) fazem parte desta polêmica, mas culminam, a nosso ver, na inevitabilidade do desenvolvimento associado e combinado e nos seus possíveis ganhos (?).

4 Que não é uma novidade latino-americana.

5 Todos os grifos desta citação reproduzidos dos originais.

6 Isso não significa, todavia, que somente existiram levantes subversivos. Ao contrário, também atuaram e atuam permanentemente ações contrarrevolucionárias inclusive com apoio popular.

7 Fonte não suspeita por se tratar de um interlocutor privilegiado do grande capital. (REAL GDP growth, [2020].

8 Estes índices certamente variarão com os dados finais de 2020.

9 Necessário ressaltar que os momentos de crescimento da economia latino-americana não significaram a redução da desigualdade social nos países da região (mesmo durante os governos mais progressistas).

10 Programas como o Bolsa Família no Brasil (governos Lula-Dilma) e a Asignación Universal por Hijo na Argentina (governos Néstor-Cristina Kirchner), entre outros similares, preservada sua inegável importância, foram programas amplamente estimulados pelo Banco Mundial que segue firmemente as orientações do FMI para a América Latina e o Caribe: rígido controle fiscal, privatizações, desregulamentação laboral, Estado centrado na pobreza extrema, superávit primário e câmbio flutuante. Os juros, nesse momento, tendencialmente em queda, mas superiores ao restante do mundo. Sobre o caso brasileiro, na visão do BID, consultar The Word Bank (2019).

11 Mesmo os robustos números chineses, jamais negativos entre 1980-2020, têm diminuído depois da crise mundial de 2008. Reduziu de 14,4 (2006-2007) para 9,7\% (entre 2007-2008), apresentando tendência de queda constante a 6,1\% (2019-2020) e previsão de 1,2\% (2020-2021 - o que seria o menor índice, de longe, nos últimos 40 anos). (REAL GDP growth, [2020]).

12 Considere-se, por exemplo, no caso da América do Sul, na Argentina e no Brasil (submetidos à desindustrialização e desnacionalização contínuas), no Chile (absolutamente desnacionalizado durante a ditadura comandada por Pinochet) e no Paraguai (não industrializado).

13 Em que Sebastian Piñera (Chile, 2011-2014 e 2018 aos dias atuais) e Mauricio Macri (Argentina, 10 de dezembro de 2015/2019), foram paradigmas político-governamentais desta retomada na América do Sul.

14 Recentemente revertido após forte mobilização popular.

15 As diferenças entre tais alternativas não podem ser niveladas e subestimadas.

16 Ilusão pensar que a derrota de Trump significa o fim da extrema-direita. 


\section{José Fernando Siqueira da Silva}

jose.siqueira-silva@unesp.br

Doutor em Serviço Social pela Pontifícia Universidade Católica de São Paulo (PUC-SP)

Professor Associado do Departamento de Serviço Social da Universidade Estadual Paulista (UNESP/ Franca)

\section{UNESP/Franca}

Eufrásia Monteiro Petráglia, 900

Jd. Dr. Antonio Petráglia - Franca/SP

CEP: $14409-160$.

\author{
Agradecimentos \\ Agradeço o apoio financeiro da Fundação de Amparo à \\ Pesquisa do Estado de São Paulo (FAPESP) e Conselho \\ Nacional de Desenvolvimento Científico e Tecnológico \\ (CNPq). \\ Agência financiadora \\ FAPESP - processo 2017/14497-5. CNPq - processo \\ 302472/2017-7.
}

\author{
Contribuições do autor \\ Não se aplica. \\ Aprovação por Comitê de Ética e consentimento para \\ participação \\ Não se aplica. \\ Consentimento para publicação \\ Consentimento do autor. \\ Conflito de interesses \\ Não há conflito de interesses.
}

